\title{
THE EFFECT OF MATERNAL TOXAEMIA AND DIABETES ON TRANSPLACENTAL GRADIENTS OF FREE AMINO ACIDS
}

\author{
BY \\ L. JOSEPH BUTTERFIELD and DONOUGH O'BRIEN \\ From the Department of Pediatrics, University of Colorado Medical Center, U.S.A.
}

(RECEIVED FOR PUBLICATION JANUARY 10, 1963)

Earlier studies (Christensen and Streicher, 1948) have demonstrated that amino nitrogen levels are greater in foetal than in maternal plasma and that this difference is lessened in toxaemia of pregnancy (Clemetson and Churchman, 1954). For normallydelivered full-term infants of healthy mothers, the mean ratio of these concentrations is $1 \cdot 7(1 \cdot 4-2 \cdot 0): 1$. Crumpler, Dent and Lindan (1950), with paper chromatography, and Glendening, Margolis and Page (1961) using continuous flow column chromatography have confirmed that this difference also holds for all common amino acids with the possible exception of proline. This study demonstrates the effect on these gradients of maternal toxaemia and diabetes.

\section{Subjects and Methods}

Umbilical vein and maternal vein samples were taken immediately after delivery from seven normal healthy fasting mothers with uncomplicated pregnancies, from three with pre-eclampsia and from two with diabetes (Table 1). Plasma aliquots were at once deproteinized (Stein and Moore, 1954) and assayed for amino acids (Moore, Spackman and Stein, 1958) using a Beckman/ Spinco amino acid analyser. No values are given for tryptophan which is not quantitatively recovered by this technique or for glutamine which is eluted with asparagine, as well as being variably destroyed during deproteinization. The reproducibility of a single plasma sample for all stages of this assay, as expressed by the coefficient of variation, ranged from $\pm 2 \cdot 6 \%$ to $\pm 7 \cdot 6 \%$ with a mean from all amino acids of $\pm 5.7 \%$ excepting half cystine and histidine, which gave values of $\pm 10 \%$.

\section{Results and Discussion}

Brief clinical details of the foetal-maternal pairs are given in Table 1; the data for the amino acid levels and for the foetal-maternal ratios (FMR) are shown in Table 2. In every instance levels are higher in the foetal plasma than in the maternal by factors that range from 1.6 to $3 \cdot 1$ to 1 . These results are in accordance with the previous observations of Glendening et al. (1961) who found similar ratios for 12 amino acids, proline excepted, in two paired and in several unpaired foetalmaternal samples.

Values for these ratios in the abnormal pregnancies are, with few exceptions, uniformly low. Individually significant differences are observed in a group of structurally unrelated amino compounds primarily for taurine, alanine and histidine as well as, to a lesser extent, for glycine and phenylalanine. Nothing is known of the effects of one amino acid on another in transport across the placenta in man; although Christensen and Streicher (1948) have shown that in the guinea-pig maternal loading with histidine, methionine or proline would inhibit transplacental glycine transport, whereas 1-glutamic acid loading would not. However, since homeostasis was not disturbed on the maternal side in these abnormal cases, it might be supposed that transport interrelations would be unchanged and that the whole pattern of differences in the foetal-maternal ratios could be judged using a binomial distribution test. If this is done as in Table 2 additional evidence is obtained of an impairment of transplacental amino acid transport in diabetes and toxaemia. From this and previous data it is not yet possible to suggest a mechanism whereby this might interfere with foetal protein metabolism.

\section{Summary}

Using the technique of continuous flow column chromatography, transplacental amino acid gradients have been shown to be significantly impaired in three subjects with pre-eclampsia and two with diabetes when compared to normal controls.

The authors gratefully acknowledge the technical assistance of Miss Dorothy Walker and the statistical advice of Dr. Alan Sexton. 
TABLE 1

CLINICAL INFORMATION ABOUT FOETAL-MATERNAL PAIRS

\begin{tabular}{|c|c|c|c|c|c|}
\hline \multirow{2}{*}{$\begin{array}{l}\text { Case } \\
\text { No. }\end{array}$} & \multicolumn{3}{|c|}{ Mother } & \multicolumn{2}{|r|}{ Infant } \\
\hline & $\begin{array}{c}\text { Age } \\
\text { (years) }\end{array}$ & Parity & $\begin{array}{c}\text { Gestational } \\
\text { Complications }\end{array}$ & $\begin{array}{c}\text { Birth Weight } \\
\text { (g.) }\end{array}$ & $\begin{array}{c}\text { Neonatal } \\
\text { Complications }\end{array}$ \\
\hline $\begin{array}{r}1 \\
2 \\
3 \\
4 \\
5 \\
6 \\
7 \\
8 \\
9 \\
10 \\
11 \\
12\end{array}$ & $\begin{array}{l}39 \\
22 \\
18 \\
21 \\
19 \\
23 \\
18 \\
20 \\
17 \\
18 \\
28 \\
20\end{array}$ & $\begin{array}{l}2 \\
0 \\
0 \\
0 \\
0 \\
1 \\
0 \\
1 \\
0 \\
0 \\
0 \\
2 \\
0\end{array}$ & $\begin{array}{c}\text { None } \\
\text { None } \\
\text { None } \\
\text { None } \\
\text { None } \\
\text { None } \\
\text { None } \\
\text { Pre-eclampsia } \\
\text { Pre-eclampsia } \\
\text { Pre-eclampsia } \\
\text { Pre-diabetes } \\
\text { Diabetes (Class B) }\end{array}$ & $\begin{array}{l}2,510 \\
3,070 \\
3,110 \\
3,750 \\
3,000 \\
2,600 \\
2,860 \\
3,500 \\
3,520 \\
3,390 \\
2,840 \\
4,030\end{array}$ & $\begin{array}{c}\text { None } \\
\text { None } \\
\text { None } \\
\text { None } \\
\text { None } \\
\text { None } \\
\text { None } \\
\text { Died: pneumonia } \\
\text { None } \\
\text { None } \\
\text { None } \\
\text { Hypoglycaemia; macrosomia }\end{array}$ \\
\hline
\end{tabular}

TABLE 2

TRANSPLACENTAL AMINO ACID GRADIENTS IN SEVEN NORMAL AND FIVE COMPLICATED PREGNANCIES

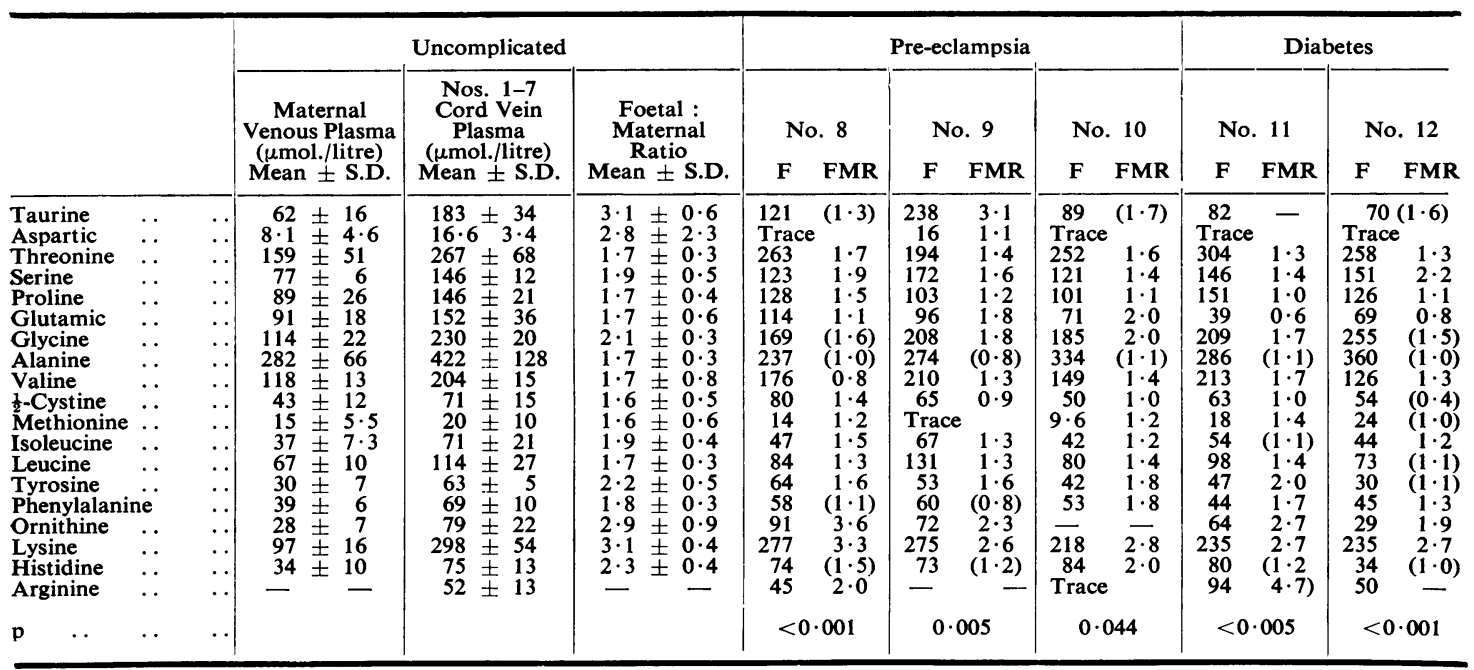

S.D. = Standard deviation with Bessel correction for small sample bias $=\sqrt{\left(\frac{E x^{2}}{n}-\bar{x}^{2}\right)\left(\frac{n}{n-1}\right)}$

$F=$ Concentration of free amino acid in cord venous plasma in $\mu$ mol./litre.

FMR = Ratio of concentration of free amino acid in cord venous plasma to that in maternal venous plasma.

$(0 \cdot 7)=$ Bracketed figure for FMR indicating $\geq-2$ S.D. from normal mean.

$\mathrm{p}=$ Probability of being normal calculated from the incidence of individual values for FMR of $\geq-2$ S.D. from normal mean according to the binomial probability distribution $(\underset{x}{x}) p^{x}(1-p)^{n-x}$ omitting values for aspartic and arginine.

The study was supported by the United States Public Health Service Grants A-1066 and FR-69-01.

\section{REFERENCES}

Christensen, H. N. and Streicher, J. A. (1948). Association between rapid growth and elevated cell concentrations of amino acids. J. biol. Chem., 175, 95

Clemetson, C. A. B. and Churchman, J. (1954). The placental transfer of amino-acids in normal and toxaemic pregnancy. J. Obstet. Gynaec. Brit. Emp., 61, 364.
Crumpler, H. R., Dent, C. E. and Lindan, O. (1950). The amino-acid pattern in human foetal and maternal plasma at delivery. Biochem. J., 47, 223.

Glendening, M. B., Margolis, A. J. and Page, E. W. (1961). Amino acid concentrations in fetal and maternal plasma. Amer. $J$. Obstet. Gynec., 81, 591.

Moore, S., Spackman, D. H. and Stein, W. H. (1958). Chromatography of amino acids on sulfonated polystyrene resins. An improved system. Analyt. Chem., 30, 1185 .

Stein, W. H. and Moore, S. (1954). The free amino acids of human blood plasma. J. biol. Chem., $211,915$. 